\title{
Functional and comparative genome analysis of novel virulent actinophages belonging to Streptomyces flavovirens
}

\author{
A. Sharaf ${ }^{1,2^{*}}$ D, F. Mercati ${ }^{3}$, I. Elmaghraby ${ }^{4}$, R. M. Elbaz ${ }^{5}$ and E. M. Marei ${ }^{6}$
}

\begin{abstract}
Background: Next Generation Sequencing (NGS) technologies provide exciting possibilities for whole genome sequencing of a plethora of organisms including bacterial strains and phages, with many possible applications in research and diagnostics. No Streptomyces flavovirens phages have been sequenced to date; there is therefore a lack in available information about $S$. flavovirens phage genomics. We report biological and physiochemical features and use NGS to provide the complete annotated genomes for two new strains (Sf1 and Sf3) of the virulent phage Streptomyces flavovirens, isolated from Egyptian soil samples.

Results: The S. flavovirens phages (Sf1 and Sf3) examined in this study show higher adsorption rates (82 and 85\%, respectively) than other actinophages, indicating a strong specificity to their host, and latent periods (15 and 30 min.), followed by rise periods of 45 and $30 \mathrm{~min}$. As expected for actinophages, their burst sizes were 1.95 and 2.49 virions per $\mathrm{mL}$. Both phages were stable and, as reported in previous experiments, showed a significant increase in their activity after sodium chloride $(\mathrm{NaCl})$ and magnesium chloride $\left(\mathrm{MgCl}_{2} \cdot 6 \mathrm{H}_{2} \mathrm{O}\right)$ treatments, whereas after zinc chloride ( $\mathrm{ZnCl}$ ) application both phages showed a significant decrease in infection.

The sequenced phage genomes are parts of a singleton cluster with sizes of 43,150 bp and 60,934 bp, respectively. Bioinformatics analyses and functional characterizations enabled the assignment of possible functions to 19 and 28 putative identified ORFs, which included phage structural proteins, lysis components and metabolic proteins.

Thirty phams were identified in both phages, 10 (33.3\%) of them with known function, which can be used in cluster prediction. Comparative genomic analysis revealed significant homology between the two phages, showing the highest hits among Sf1, Sf3 and the closest Streptomyces phage (VWB phages) in a specific 13Kb region. However, the phylogenetic analysis using the Major Capsid Protein (MCP) sequences highlighted that the isolated phages belong to the BG Streptomyces phage group but are clearly separated, representing a novel sub-cluster.
\end{abstract}

Conclusion: The results of this study provide the first physiological and genomic information for S. flavovirens phages and will be useful for pharmaceutical industries based on S. flavovirens and future phage evolution studies.

Keywords: Bacteriophage, Biological stability, Whole genome sequence, NGS, Comparative genomics

\footnotetext{
*Correspondence: sharaf@paru.cas.cz

'Genetic Department, Faculty of Agriculture, Ain Shams University, Cairo

11241, Egypt

${ }^{2}$ Institute of Parasitology, Biology Centre, Czech Academy of Sciences, 37005

České Budějovice, Czechia

Full list of author information is available at the end of the article
} 


\section{Background}

Bacteriophages (phages), natural viral predators of bacteria, are engaged in a constant evolutionary arms race with their hosts [1], playing major roles in the ecological balance of microbial life and in microbial diversity.

Most double-stranded DNA (dsDNA) phages share the same gene pool [2]; however, sequence comparisons reveal a widespread horizontal exchange of sequences among genomes, mediated by both non-homologous and homologous recombination. High frequency exchange among phages occupying similar ecological niches results in a high rate of mosaic diversity in local populations [3]. Studies confirm that phage genomes are mosaics and represent a large common genetic pool due to horizontal exchange $[4,5]$.

The screening of microbial natural products continues to constitute an important route to the discovery of chemicals for developing new therapeutic agents and evaluating the therapeutic potential of bacterial taxa [6-8]. In this respect, actinomycetes are a group of microorganisms mostly used in biotechnology for handling bioactive compounds. $[9,10]$. Moreover, bacteriophages can be used to detect antiviral compound production by actinomycetes. Finally, actinophages are isolated and investigated because they can influence antibiotic production in bacterial strains, causing problems in the pharmaceutical industry. The vast majority of actinophages were isolated from sediments, but direct isolation from soil generally yields extremely low titers $[11,12]$. However, although it is difficult to grow bacteriophages from soil without enrichment, a wide range of counts has been reported [13, 14].

Recently, there has been expanding interest in bacteriophages that infect Streptomyces species, since the phages can support the development of cloning vectors [15]. Such vectors could open the way for genetic manipulation as an important tool for Streptomyces improvement. Moreover, the mechanisms of the system for phage infection and multiplication could be useful in the fermentation industry and lead to the development of phage cloning vectors [16]. To date, no studies on phages isolated from S. flavovirens, an important source for several pharmaceutical drugs, such as actinomycin complex, mureidomycin and pravastatin $[17,18]$, have been carried out.

The development of high-throughput NGS (Next Generation Sequencing) technologies $[19,20]$ and the possibility to sequence entire genomes or transcriptomes more efficiently and economically than with first generation sequencing strategies permitted the collection of large amounts of information and the analysis of sequences from hundreds of thousands of species. Therefore, the dawn of next generation sequencing technologies has opened up exciting possibilities for whole genome sequencing in a wide range of organisms and the bacterial viruses have not been excluded from this revolution, despite the fact that their genomes are orders of magnitude smaller in size compared with bacteria and other organisms.

The Actinophage Sequence Databases (http://phagesdb. org/) currently include 5861 genomes from putative actinophages, 120 of which infect Streptomyces species and sixty-five of which are sequenced, but no genomes of phages isolated form S. flavovirens are currently available. The NCBI genome database contains around 600 Caudovirales genomes to date but the number of complete bacteriophage genomes published is growing slowly [21].

Until now, no phages belonging to S. flavovirens have been sequenced and relatively little is known about $S$. flavovirens phage genomics. In the present work, we report the first whole genome sequencing study and annotation of two S. flavovirens virulent phages. The results will provide an important genomic resource for future investigations in the bacteriophages related to $S$. flavovirens and for phage evolution studies.

\section{Methods \\ Source of lytic actinophages}

Two isolates of Streptomyces flavovirens phages, named Sf1 and Sf3, were obtained from the virology lab, Agric. Microbiology Department, Faculty of Agriculture, Ain Shams University, Cairo, Egypt. Phages were isolated from soil and the morphological properties were analyzed by standard methodology and reported in Marei and Elbaz (2013) [22].

\section{Purification of lytic actinophages}

The high titer phage suspension of each isolated phage was prepared using a liquid culture enrichment technique. The high titer phage suspension of each phage was ultracentrifuged at $30000 \mathrm{rpm}$ for $90 \mathrm{~min}$. at $4{ }^{\circ} \mathrm{C}$ in a Beckman L7-35 ultracentrifuge. The pellet was gently resuspended in $0.5 \mathrm{ml}$ of $0.2 \mathrm{M}$ phosphate buffer $\mathrm{pH} 7.2$ [23].

\section{Adsorption rate and one-step growth experiments}

The adsorption experiments were carried out with two isolated phage suspensions added to spores of their indicator host (S. flavovirens). Suspensions of each phage were incubated at $30{ }^{\circ} \mathrm{C}$ with gentle shaking. Samples were withdrawn at regular intervals after inoculation.

The mycelial fragments of the indicator strain were removed by centrifugation and the concentration of phage remaining in the supernatant was counted. The adsorption rates of the two phages were determined by measuring residual plaque-forming ability in membrane-filtered samples of an attachment mixture [24] and the adsorption rate constant $\mathrm{k}(\mathrm{mL} / \mathrm{min})$ was calculated [25]. The one-step growth experiment was performed as described by Dowding (1973) [24]. 


\section{Physiochemical stability}

To evaluate the phages' stability three different chemicals $(\mathrm{NaCl}, \mathrm{MgCl} 2.6 \mathrm{H} 2 \mathrm{o}$ and $\mathrm{ZnCl} 2)$, were used. Five concentrations $(0.1,0.2,0.3,0.4$ and $0.5 \mathrm{mM})$ for each salt were employed [26]. To test the effect of different treatments phage solutions for both tested strains with final concentrations of $10^{7} \mathrm{PFU} / \mathrm{ml}$ were utilized. The mixture was incubated for $10 \mathrm{~min}$ at room temperature (RT). The number of plaques was determined using the double layer method (plaque assay test) [27]. A control test was prepared by mixing bacterial suspension with phage without the tested chemicals.

\section{DNA isolation, library preparation and whole genome sequencing}

Genomic DNA was isolated from the propagated phages according to the procedure described by Kieser et al. [28]. DNA quality was assessed using a Nanodrop Bioanalyzer ND1000 (ThermoScientific). Sequencing libraries were prepared by shearing $1 \mu \mathrm{g}$ of DNA in blunt-ended fragments by linking the Ion adapters using an Ion XpressTM Plus Fragment Library Kit (Life Technologies, Carlsbad, USA) according to the manufacturer's specifications. The sized and ligated fragments were amplified by emulsion-PCR using the Ion OneTouch 200 Template kit (Life Technologies, Carlsbad, USA). Quality and insert size distribution were assessed using an Agilent Bioanalyzer DNA 1000 chip. Libraries were sequenced on an Ion Torrent PGM semiconductor sequencer (Life Technologies, Carlsbad, USA) using the 200 bp protocol and an Ion Torrent 314 chip following the manufacturer instructions (Life Technologies, Carlsbad, USA).

\section{Assembly and bioinformatics analyses}

Raw reads resulting from Sf1 and Sf3 sequencing were trimmed using Trimmomatic with single end mode (no quality encoding was specified to allow the program to determine it automatically [29]) and assembled separately using the gsAssembler (Roche Applied Science, Indianapolis, IN); the Graphical User Interface (GUI) version was used with the default parameters. The collected contigs were visualized and validated using Hawkeye [30]. Resulting contigs for each phage showed approximately 60 -fold sequence read coverage. The expected sequence accuracy was $95 \%$ with a statistical error of less than 1 in 10,000 bp. Sequence homologies were determined by using BLASTn against the actinophage database to assign the phages to a cluster [31].

\section{Open reading frame (ORF) analysis and gene prediction}

Open reading frames (ORFs) were identified and the genome sequences of each phage were annotated as described previously in Dobbins et al., 2004 by using DNA Master (J. G. Lawrence) (http://cobamide2.bio.pitt.edu) software and visual inspection [32]. For a genome-wide viewpoint an association with the annotation refinement, functional analysis and other explorations was developed using Phamerator. Protein sequence relationships and conserved domains within genes were also studied. Gene products were grouped into "Phamilies" generally referred to as "Phams", or groups of proteins with a high degree of similarity to one another. The pairwise alignment scores and significant rate were determined using BLASTp and ClustalW [33].

\section{Genomic comparisons between the sequenced and the close related phages}

Sequence comparisons were performed by using the BLAST algorithm available at NCBI [34] and Mauve software [35]. A comparison map among Sf1 and Sf3 Streptomyces phages and closely related phages (VWB and SV1) with available genomes in the National Center for Biotechnology Information (NCBI) nucleotide database (https://www.ncbi.nlm.nih.gov/) was generated by Circoletto (http://tools.bat.infspire.org/circoletto/) [34, 36]. For pictogram construction, bit-score values were used to describe the quality of the alignment at a given point. The bit-score is a normalized version of the score value returned by the BLAST searches, expressed in bits [37].

The phylogenetic tree of Major Capsid Protein (MCP) genes from two new isolated phages (Sf1 and Sf3) and 20 related Streptomyces phages available in the NCBI database was constructed with Geneious software version (R8) (http://www.geneious.com) [38] based on the Neighbor-Joining (NJ) algorithm.

\section{Results and discussion}

\section{Adsorption rate constant and growth characteristics of isolated phages}

Adsorption of Sf1 and Sf3 was determined using S. flavovirens cells grown in phage medium to the early exponential phase of growth (15-h cultures). About 82 and $85 \%$ of all infective Sf1 and Sf3 particles, respectively, were adsorbed within 20 min of contact. The adsorption reached a maximum after $30 \mathrm{~min}$. for both phages. The adsorption constant $\mathrm{K}$ was $3.66 \mathrm{pL} / \mathrm{min}$ for Sf1 and 3.80 $\mathrm{pL} / \mathrm{min}$ for Sf3, determined by the Adams's formula [27]. The phages adsorption rates were higher than other actinophages [39], which was probably due to the strong specificity of the Sf1 and Sf3 phages to their host.

The production of Sf1 and Sf3 phages were determined in a one-step growth experiment at $30{ }^{\circ} \mathrm{C}$. Results revealed that the latent periods of Sf1 and Sf3 were approximately 15 and 30 mins, respectively. After 30 and 45 mins the maximum rise period was shown and the burst sizes were 1.95 and $2.49 \mathrm{PFU} / \mathrm{mL}$ for Sf1 and Sf3, respectively (Fig. 1). The present results are in agreement with the data obtained from a study on 24 


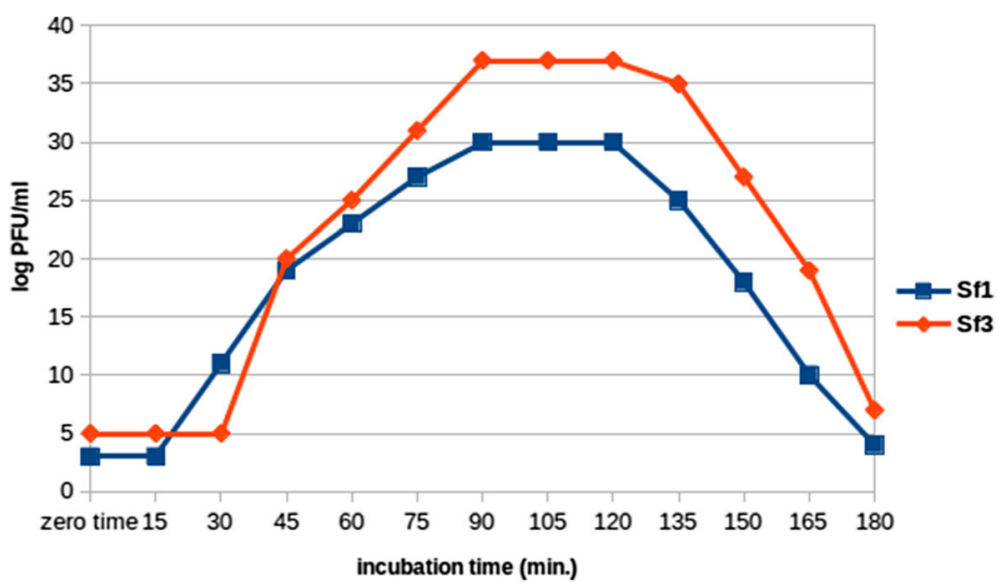

Fig. 1 One-step growth experiment for Sf1 and Sf3 phages development on S. flavovirens at $30^{\circ} \mathrm{C}$

actinophages [40], underlining that under controlled cultural conditions the infection of isolated Streptomycetes cells by phages was varied.

\section{Physiochemical stability of isolated actinophages}

Sodium and magnesium chloride treatments yielded a significant increase in both phages' activity for all concentrations used compared with the control, while zinc chloride application with concentrations $>0.3 \mathrm{mM}$ caused a significant decrease of activity for Sf1 and Sf3 (Fig. 2). Similar results were reported in previous studies [41-43]. Absence of calcium and magnesium ions prevents adsorption and the lysis cycle, while their presence stimulates a significant increase in phage activity, probably due to the increase of adsorption and penetration rates. On the contrary, zinc and aluminum chloride showed significant loss of infectivity in both phages. This is in accordance with the experiments performed by Robert and Charles, which suggested that aluminum caused viral inactivation related to the dissociation of viral capsid proteins [44].

\section{Genome organization of phages Sf1 and Sf3}

Genome sequencing generated 69,719 and 107,273 reads for each phage with around 60-fold coverage and 43,150 bp, and 60,934 bp assembled sequences for Sf1 and Sf3, respectively. The pair-wise alignment [45] revealed that the genomes of Sf1 and Sf3 shared an overall high level of similarity, with conserved regions of high identity (100\% identity) interspersed between regions with high variability (ranging from $23.9 \%$ to $87.5 \%$ ) (Fig. 3a). A similar mosaic genome structure has been observed in most other phage genomes, indicating extensive horizontal genetic exchange among phages [46-49]. No close relatives (Singleton) from modeling of both genome construction were revealed (Fig. 1).

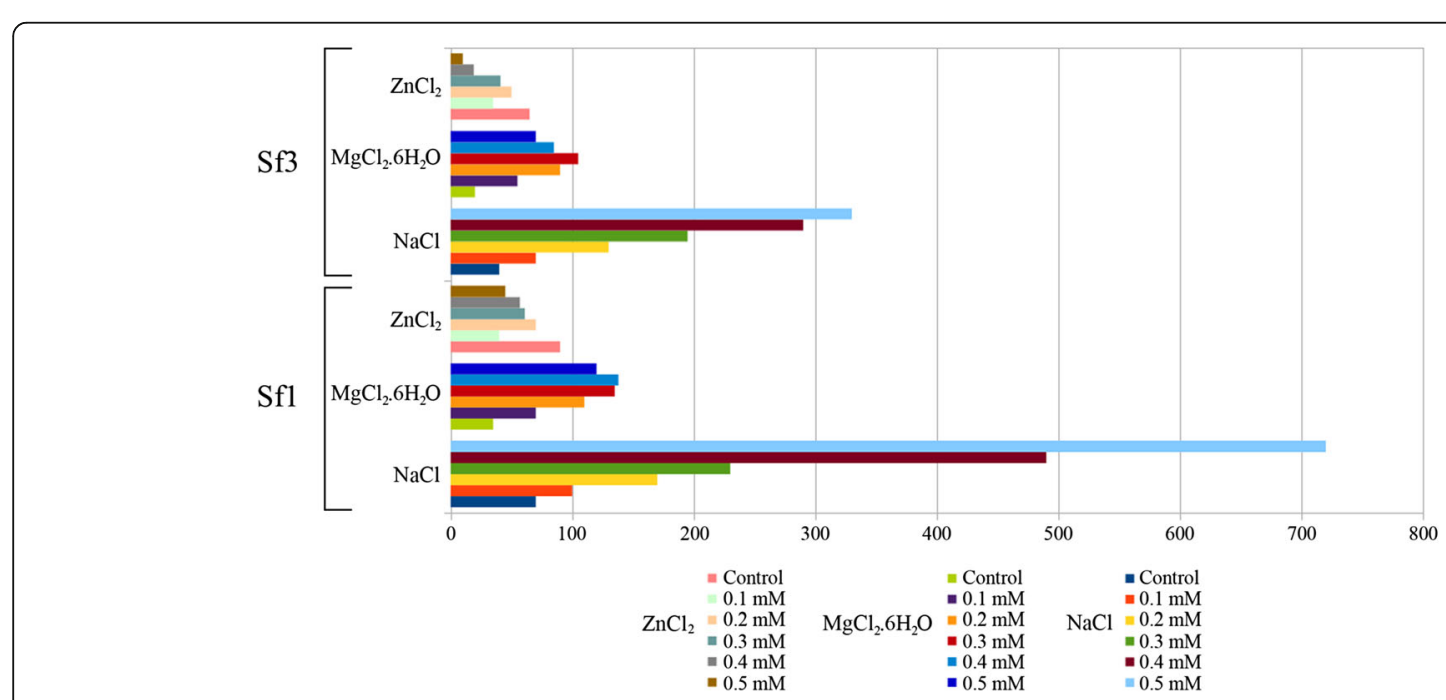

Fig. 2 Effect of three different chemicals on the Sf1 and Sf3 infectivity 


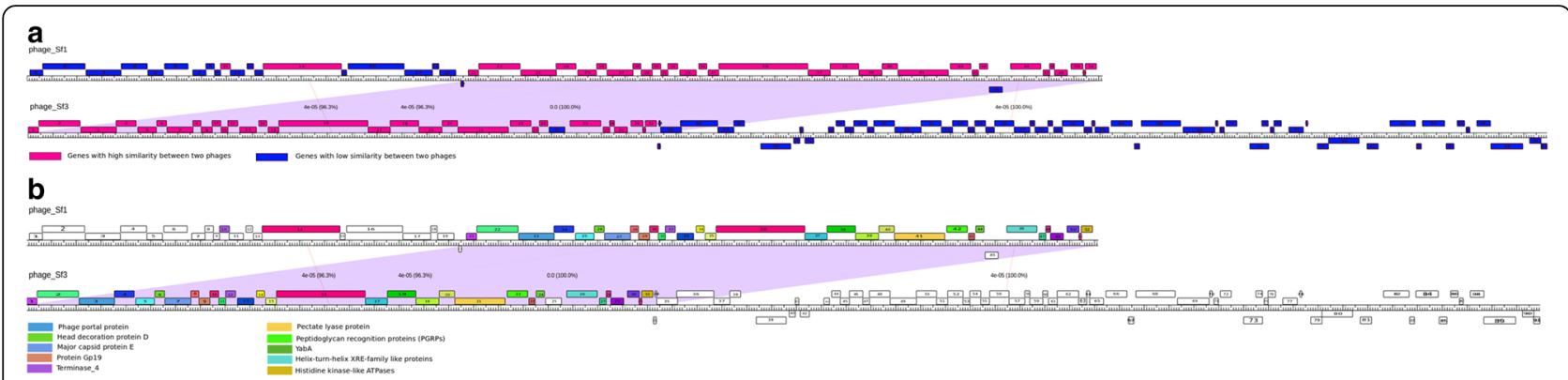

Fig. 3 Genomic organization of Sf1 and Sf3 phages. Phages were mapped using Phamerator; the purple lines between phages underline the regions with high similarity, while the ruler corresponds to genome base pairs. The predicted genes are shown as boxes either above or below the genome (ruler), depending on whether are rightwards or leftwards transcribed, respectively. Gene numbers are shown within each box; pink boxes refereed to the genes with high similarity between two phages while the blue boxes refereed to the genes that show low similarity. a The phages maps showed by cluster conservation. b The phages maps showed by phams; genes are colored according to their function categories "phams"

Annotation of Sf1 and Sf3 genomes revealed 52 and 91 putative ORFs, respectively. According to their homology, 19 out of 52 ORFs (36.5\%) from Sf1 and 28 out of $91(30.8 \%)$ from the Sf3 genome have been assigned functions compared to known conserved domains [50] (Tables 1 and 2). Isolated genes were mainly involved in DNA replication and repair, nucleotide metabolism, lysis, phage structural proteins and other enzymes. The results obtained are in agreement with other bacteriophage studies [51-53]. Phage Sf1 showed 52 ORFs (Table 1), named gp1 - gp52, while 91 ORF were identified from Phage Sf3, from gp1 to gp91 (Table 2). The majority of members of identified families are bacteriophage proteins, while others (75\%) have unknown function $[54,55]$.

\section{Phage structure and assembly genes}

Several genes code for terminase subunit proteins, such as gp1 and 2 which code for terminase_4 (pfam05119) and terminase_1 (pfam03354) super-families, respectively. The gp3 and gp23 genes encode for the phage portal protein (pfam05133), an important protein involved in DNA transport during its packaging and ejection. Another relevant gene is gp6 which, together with gp27,codes for the major capsid protein (PHA00665) [56] and the major capsid protein E domain (pfam03864) [57], respectively, involved in the stabilization of the condensed form of DNA in phage heads. Some genes involved in tail development, gp14 (pfam10145) and gp17 (pfam13550), were also identified.

In Sf3we found a gene (gp3) encoding phage portal protein (pfam05133), crucial for DNA migration and building the junction between head and tail proteins [58], and others, such as gp7 and gb16, that encode for the major capsid protein E domain (pfam03864) [57] or for lyase (gp21), like pectate lyase_3 superfamily protein (pfam12708). A phage putative head morphogenesis protein (TIGR01641) of 110 amino acids found exclusively in phage-related proteins, was encoded by gp84. Putaive head morphogenesis proteins such as gp85, which encodesthe transcriptional activator RhaR (PRK13502), and gp89, involved in the phage terminase_3 (COG1783) synthesis, are activated during the beginning of doublestranded viral DNA packaging [59].

\section{DNA replication and metabolic genes}

The gp44 gene encodes YabA (COG4467), a protein that interacts with the DnaA initiator and the DnaN sliding clamp and drives the control of DNA replication initiation [60, 61]. gp46 and gp52 encode for helix-turn-helix XRE-family like proteins (cd00093) [62] and histidine kinase-like ATPases (cd00075) [63], respectively, two important binding proteins with roles in the replication, repair, storage and modification of DNA. gp4 encodes a protein belonging to the MATE family (cd13126), which functions as a translocase for lipopolysaccharides [64], while gp5 codes for the golgin subfamily protein A5, a protein responsible for maintaining Golgi structure in intra-Golgi retrograde transport [65].

ORFs with the same biological roles were also identified in Sf3 phage. Indeed gp35 encodes for a HhH-GPD superfamily base excision DNA repair protein (pfam00730). This group includes endonuclease III, 8-oxoguanine DNA glycosylases and DNA-3-methyladenine glycosylase II [66]. Other members include different types of DNA and RNA exonucleases such as RNase T, oligoribonuclease, and RNA exonuclease (REX) [67]; Holliday junction resolvases (HJRs) (cd00529), endonucleases structurally similar to RNase $\mathrm{H}$ and Hsp70, which specifically resolve Holliday junction DNA intermediates during homologous recombination was encoded by gp52 [68]. Gp76 encodes for HNH nucleases (cd00085), an endonuclease signature which is found in viral, prokaryotic and eukaryotic proteins [69]. 
Table 1 Overview of Sf1 phage ORFs, summary of homology searches and annotations

\begin{tabular}{|c|c|c|c|c|c|c|c|c|c|}
\hline ORF & Product & Strand & Begin & End & $\mathrm{AA}$ & Motif & Predicted functions & Homology score & E-value \\
\hline ORF 1 & gp1 & + & 126 & 650 & 175 & pfam05119 & Terminase_4 superfamily & 65,72 & $1.77 \mathrm{e}-14$ \\
\hline ORF 2 & gp2 & + & 643 & 2349 & 569 & pfam03354 & Terminase_1 superfamily & 243 & $3.32 \mathrm{e}-73$ \\
\hline ORF 3 & gp3 & + & 2376 & 3785 & 470 & pfam05133 & Phage portal protein & 147 & $3.13 e-39$ \\
\hline ORF 4 & gp4 & + & 3796 & 4842 & 349 & cd13126 & (MATE) proteins & 36,9 & $5.07 e-03$ \\
\hline ORF 5 & gp5 & + & 4857 & 5480 & 208 & pfam09787 & Golgin subfamily A5 & 35,58 & $6.35 \mathrm{e}-03$ \\
\hline ORF 6 & gp6 & + & 5535 & 6479 & 315 & PHA00665 & major capsid protein & 42,17 & $9.33 e-05$ \\
\hline ORF 7 & gp7 & + & 6661 & 7194 & 178 & - & - & - & - \\
\hline ORF 8 & gp8 & + & 7191 & 7532 & 114 & - & - & - & - \\
\hline ORF 9 & gp9 & + & 7532 & 7783 & 84 & PRK14573 & bifunctional D-alanyl-alanine synthetase & 34,02 & $2.66 \mathrm{e}-03$ \\
\hline ORF 10 & gp10 & + & 7783 & 8178 & 132 & - & - & - & - \\
\hline ORF 11 & gp11 & + & 8168 & 8740 & 191 & - & - & - & - \\
\hline ORF 12 & gp12 & + & 8843 & 9109 & 89 & - & - & - & - \\
\hline ORF 13 & gp13 & + & 9145 & 9489 & 115 & - & - & - & - \\
\hline ORF 14 & gp14 & + & 9493 & 12630 & 1046 & pfam10145 & Phage-related minor tail protein & 88,94 & $1.30 \mathrm{e}-19$ \\
\hline ORF 15 & gp15 & + & 12631 & 12837 & 69 & - & - & - & - \\
\hline ORF 16 & gp16 & + & 12896 & 15148 & 751 & - & - & - & - \\
\hline ORF 17 & gp17 & + & 15163 & 16281 & 373 & pfam13550 & Putative phage tail protein & 43,42 & $1.33 e-05$ \\
\hline ORF 18 & gp18 & + & 16281 & 16538 & 86 & - & - & - & - \\
\hline ORF 19 & gp19 & + & 16563 & 17216 & 218 & - & - & - & - \\
\hline ORF 20 & gp20 & - & 17411 & 17518 & 36 & - & - & - & - \\
\hline ORF 21 & gp21 & + & 17716 & 18126 & 137 & - & - & - & - \\
\hline ORF 22 & gp22 & + & 18141 & 19799 & 553 & - & - & - & - \\
\hline ORF 23 & gp23 & + & 19824 & 21251 & 476 & pfam05133 & Phage portal protein & 129 & $4.91 \mathrm{e}-33$ \\
\hline ORF 24 & gp24 & + & 21244 & 22044 & 267 & - & - & - & - \\
\hline ORF 25 & gp25 & + & 22107 & 22856 & 250 & - & - & - & - \\
\hline ORF 26 & gp26 & + & 22870 & 23265 & 132 & pfam02924 & Bacteriophage lambda head decoration protein D & 47,27 & $2.61 \mathrm{e}-08$ \\
\hline ORF 27 & gp27 & + & 23280 & 24326 & 349 & pfam03864 & Phage major capsid protein $\mathrm{E}$ & 62,35 & $3.13 e-11$ \\
\hline ORF 28 & gp28 & + & 24323 & 24646 & 108 & - & - & - & - \\
\hline ORF 29 & gp29 & + & 24652 & 25095 & 148 & pfam09355 & Phage protein Gp19 & 33,61 & $5.91 \mathrm{e}-03$ \\
\hline ORF 30 & gp30 & + & 25092 & 25445 & 118 & - & - & - & - \\
\hline ORF 31 & gp31 & + & 25442 & 25726 & 95 & - & - & - & - \\
\hline ORF 32 & gp32 & + & 25726 & 26127 & 134 & - & - & - & - \\
\hline ORF 33 & gp33 & + & 26200 & 26865 & 222 & - & - & - & - \\
\hline ORF 34 & gp34 & + & 26969 & 27292 & 108 & - & - & - & - \\
\hline ORF 35 & gp35 & + & 27337 & 27765 & 143 & - & - & - & - \\
\hline ORF 36 & gp36 & + & 27772 & 31344 & 1191 & cd00254 & Lytic Transglycosylase (LT) & 56,65 & $1.82 \mathrm{e}-09$ \\
\hline ORF 37 & gp37 & + & 31349 & 32239 & 297 & - & - & - & - \\
\hline ORF 38 & gp38 & + & 32239 & 33384 & 382 & - & - & - & - \\
\hline ORF 39 & gp39 & + & 33386 & 34312 & 309 & - & - & - & - \\
\hline ORF 40 & gp40 & + & 34326 & 34943 & 206 & - & - & - & - \\
\hline ORF 41 & gp41 & + & 34953 & 36977 & 675 & pfam12708 & Pectate lyase_3 superfamily protein & 73,24 & $8.54 \mathrm{e}-15$ \\
\hline ORF 42 & gp42 & + & 37059 & 37886 & 276 & cd06583 & Peptidoglycan recognition proteins (PGRPs) & 58,45 & 4.03e-11 \\
\hline ORF 43 & gp43 & + & 37933 & 38184 & 84 & - & - & - & - \\
\hline ORF 44 & gp44 & + & 38228 & 38560 & 111 & COG4467 & YabA & 34,76 & $9.25 \mathrm{e}-04$ \\
\hline
\end{tabular}


Table 1 Overview of Sf1 phage ORFs, summary of homology searches and annotations (Continued)

\begin{tabular}{|c|c|c|c|c|c|c|c|c|c|}
\hline ORF 45 & gp45 & - & 38602 & 39129 & 176 & - & - & - & - \\
\hline ORF 46 & gp46 & + & 39475 & 40689 & 405 & cd00093 & Helix-turn-helix XRE-family like proteins & 45,24 & $1.45 \mathrm{e}-06$ \\
\hline ORF 47 & gp47 & + & 40777 & 41046 & 90 & - & - & - & - \\
\hline ORF 48 & gp48 & + & 41043 & 41237 & 65 & - & - & - & - \\
\hline ORF 49 & gp49 & + & 41234 & 41752 & 173 & - & - & - & - \\
\hline ORF 50 & gp50 & + & 41901 & 42383 & 161 & - & - & - & - \\
\hline ORF 51 & gp51 & + & 42383 & 42481 & 33 & - & - & - & - \\
\hline ORF 52 & gp52 & + & 42474 & 42923 & 150 & cd00075 & Histidine kinase-like ATPases & 36,09 & $4.50 \mathrm{e}-04$ \\
\hline
\end{tabular}

\section{Cell lysis genes}

Crucial genes implicated in lysis activities, such as the cell wall degradation process in bacteria during host infection, were identified in the Sf1 genome. Indeed, gp36 encodes for the lytic transglycosylase (LT) (cd00254) that catalyzes the cleavage of the beta-1,4-glycosidic bond between $\mathrm{N}$-acetylmuramic acid and $\mathrm{N}$-acetyl-Dglucoseamine, similar to "goose-type" lysozymes. gp42 encodespeptidoglycan recognition proteins (PGRPs) (cd06583), namely receptors that bind and hydrolyze peptidoglycans of bacterial cell walls, and contains two conserved histidines and a cysteine, typical residues of zinc binding sites [70].

While gp21 is included in the pectate lyase superfamily (pfam12708), proteins with a beta helical structure like pectate lyase and most closely related to glycosyl hydrolase family and gp22 encodes to Peptidoglycan recognition proteins (PGRPs) (cd06583) [70], were identified in Sf3 genome.

Both phage genomes show up to bring a modular organization, with genes of related function clustered together (Fig. 3a and b). DNA sequences of the first $13 \mathrm{~kb}$ in Sf3 are highly similar to the last DNA sequences in Sf1 and encode for DNA packaging structural proteins (Fig. 3b).

On the basis of the amino acid sequence similarity between the gene products, the conserved pfam05133 motif and the gene locations, orf3 is predicted to encode a portal protein in both phages. No small terminaseencoding gene could be identified in either genome. The largest gene in Sf1 genome is located in orf36 (3.5 kb) encoding the lytic transglycosylase (LT), while the largest one in Sf3 genome with the same length is orf16, encoding the major capsid protein E domain. [48, 71, 72]. A possible lyase gene is positioned distinctively in both phage genomes (orf41 for Sf1 and orf21 for Sf3). Those genes located downstream in both phage genomes encode proteins involved in DNA synthesis, metabolism and repair (Fig. 3b).

\section{Evolutionary relationship of Sf1 and Sf3}

Sf1 and Sf3 phages show 30 phams, where 29 out of 30 phams contain two members (Table 3), while three members belong to pham number 12 . Ten phams (33.3\%) were assigned with known functionality; the others are unknown. Therefore, some of these phams are informative and can be used in evolutionary studies. Indeed, as reported for mycobacteriophages [73], single, ubiquitous, semi-conserved genes can be utilized for cluster prediction, useful when the whole genome sequence is unavailable. The 30 identified phams, which include important genes (see below), underline a close phylogenetic relationship between the two isolated phages and provide important information that can be used in future evolutionary relationship studies by comparing the genes identified in the Streptomyces flavovirens phages and homologous genes in other bacteriophages.

orf27 (Sf1) and orf7 (Sf3) as members of pham n.7 were assigned as phage major capsid protein (MCP) E domains; this important class of genes was also used as a single gene prediction system for the mycobacteriophage clusters analysis [73]. orf23 (Sf1) and orf3 (Sf3), members of pham n. 3, were classified as phage portal proteins. These proteins were used in some previous investigations as a marker of diversity indicating, in some cases, the connections between habitat properties, microbial community structure and phage community composition [74]. orf29 (Sf1) and orf9 (Sf3) are the members of pham n.9, were assigned to phage protein gp19, an important tail component. Most of the proteins forming the phage tail components as well as other needle-like assemblies (e.g. secretion systems and bacteriocins) have a common origin from a single protein module [74]. This evidence emphasizes the importance of phage protein diversification and specialization in the evolution of different and complex bacterial systems and in bacterial adaptation, developing new functions and providing a distinct selective advantage [74].

As expected, the virulent phages developed phams involved in lysogenic pathways. Indeed, orf41 (Sf1) and orf21 (Sf3), grouped in pham n.20, showed high homology to the pectate lyase superfamily protein that can modify the properties of polysaccharides. Since the pectinolytic protein family is commonly represented in prokaryotic and eukaryotic microorganisms and, in plants, 
Table 2 Overview of Sf3 phage, ORFs, summary of homology searches and annotations

\begin{tabular}{|c|c|c|c|c|c|c|c|c|c|}
\hline ORF no. & Product & Strand & Begin & End & AA & Motif & Predicted functions & Homology score & E-value \\
\hline ORF 1 & gp1 & + & 16 & 426 & 137 & - & - & - & - \\
\hline ORF 2 & gp2 & + & 441 & 2099 & 553 & - & - & - & - \\
\hline ORF 3 & gp3 & + & 2124 & 3551 & 476 & pfam05133 & Phage portal protein_Gp6 & 129 & $4.91 e-33$ \\
\hline ORF 4 & gp4 & + & 3544 & 4344 & 267 & - & - & - & - \\
\hline ORF 5 & gp5 & + & 4407 & 5156 & 250 & - & - & - & - \\
\hline ORF 6 & gp6 & + & 5176 & 5565 & 130 & pfam02924 & Bacteriophage lambda head decoration protein $\mathrm{D}$ & 46,5 & $5.02 \mathrm{e}-08$ \\
\hline ORF 7 & gp7 & + & 5580 & 6626 & 349 & pfam03864 & Phage major capsid protein $\mathrm{E}$ & 62,35 & $3.13 e-11$ \\
\hline ORF 8 & gp8 & + & 6623 & 6946 & 108 & - & - & - & - \\
\hline ORF 9 & gp9 & + & 6952 & 7395 & 148 & pfam09355 & Phage protein Gp19 & 33,61 & $5.91 \mathrm{e}-03$ \\
\hline ORF 10 & gp10 & + & 7392 & 7745 & 118 & - & - & - & - \\
\hline ORF 11 & gp11 & + & 7748 & 8026 & 93 & - & - & - & - \\
\hline ORF 12 & gp12 & + & 8026 & 8427 & 134 & - & - & - & - \\
\hline ORF 13 & gp13 & + & 8500 & 9165 & 222 & - & - & - & - \\
\hline ORF 14 & gp14 & + & 9269 & 9592 & 108 & - & - & - & - \\
\hline ORF 15 & gp15 & + & 9637 & 10065 & 143 & - & - & - & - \\
\hline ORF 16 & gp16 & + & 10072 & 13644 & 1191 & pfam03864 & Phage major capsid protein $\mathrm{E}$ & 62,35 & $3.13 e-11$ \\
\hline ORF 17 & gp17 & + & 13649 & 14539 & 297 & - & - & - & - \\
\hline ORF 18 & gp18 & + & 14539 & 15684 & 382 & - & - & - & - \\
\hline ORF 19 & gp19 & + & 15686 & 16612 & 309 & - & - & - & - \\
\hline ORF 20 & gp20 & + & 16626 & 17243 & 206 & - & - & - & - \\
\hline ORF 21 & gp21 & + & 17253 & 19277 & 675 & pfam12708 & Pectate lyase superfamily protein & 73,24 & $8.54 \mathrm{e}-15$ \\
\hline ORF 22 & gp22 & + & 19359 & 20186 & 276 & cd06583 & Peptidoglycan recognition proteins (PGRPs) & 58,45 & $4.03 e-11$ \\
\hline ORF 23 & gp23 & + & 20233 & 20484 & 84 & - & - & - & - \\
\hline ORF 24 & gp24 & + & 20528 & 20860 & 111 & COG4467 & YabA & 34,76 & $9.25 \mathrm{e}-04$ \\
\hline ORF 25 & gp25 & + & 20908 & 21546 & 213 & PHA03169 & hypothetical protein; Provisional & 35,72 & $5.62 \mathrm{e}-03$ \\
\hline ORF 26 & gp26 & + & 21757 & 22989 & 411 & cd00093 & Helix-turn-helix XRE-family like proteins. & 45,24 & $1.33 e-06$ \\
\hline ORF 27 & gp27 & + & 23077 & 23346 & 90 & - & - & - & - \\
\hline ORF 28 & gp28 & + & 23343 & 23537 & 65 & - & - & - & - \\
\hline ORF 29 & gp29 & + & 23534 & 24052 & 173 & - & - & - & - \\
\hline ORF 30 & gp30 & + & 24201 & 24683 & 161 & - & - & - & - \\
\hline ORF 31 & gp31 & + & 24668 & 24781 & 38 & - & - & - & - \\
\hline ORF 32 & gp32 & + & 24774 & 25223 & 150 & cd00075 & Histidine kinase-like ATPases & 36,09 & $4.50 \mathrm{e}-04$ \\
\hline ORF 33 & gp33 & - & 25247 & 25363 & 39 & - & - & - & - \\
\hline ORF 34 & gp34 & + & 25319 & 25381 & 21 & - & - & - & - \\
\hline ORF 35 & gp35 & + & 25382 & 26221 & 280 & pfam00730 & HhH-GPD superfamily base excision DNA repair protein & 47,36 & $3.71 \mathrm{e}-07$ \\
\hline ORF 36 & gp36 & + & 26181 & 27680 & 500 & - & - & - & - \\
\hline ORF 37 & gp37 & + & 27677 & 28327 & 217 & cd01672 & Thymidine monophosphate kinase (TMPK) & 112 & $1.37 e-30$ \\
\hline ORF 38 & gp38 & + & 28324 & 28755 & 144 & cd04683 & the Nudix hydrolase superfamily & 153 & $3.17 \mathrm{e}-48$ \\
\hline ORF 39 & gp39 & - & 29387 & 30592 & 402 & - & - & - & - \\
\hline ORF 40 & gp40 & - & 30712 & 30963 & 84 & - & - & - & - \\
\hline ORF 41 & gp41 & + & 30962 & 31105 & 48 & - & - & - & - \\
\hline ORF 42 & gp42 & - & 31162 & 31524 & 121 & cd00093 & Helix-turn-helix XRE-family like proteins. & 41 & $1.99 \mathrm{e}-06$ \\
\hline ORF 43 & gp43 & + & 32113 & 32337 & 75 & - & - & - & - \\
\hline ORF 44 & gp44 & + & 32425 & 32778 & 118 & - & - & - & - \\
\hline ORF 45 & gp45 & + & 32771 & 33139 & 123 & - & - & - & - \\
\hline
\end{tabular}


Table 2 Overview of Sf3 phage, ORFs, summary of homology searches and annotations (Continued)

\begin{tabular}{|c|c|c|c|c|c|c|c|c|c|}
\hline ORF 46 & gp46 & + & 33136 & 33678 & 181 & - & - & - & - \\
\hline ORF 47 & gp47 & + & 33675 & 33947 & 91 & - & - & - & - \\
\hline ORF 48 & gp48 & + & 33944 & 34774 & 277 & pfam12705 & PD-(D/E)XK nuclease superfamily & 34,99 & $5.68 \mathrm{e}-03$ \\
\hline ORF 49 & gp49 & + & 34777 & 35838 & 354 & - & - & - & - \\
\hline ORF 50 & gp50 & + & 35835 & 36647 & 271 & cd06127 & DEDDh $3^{\prime}-5^{\prime}$ exonuclease domain family & 111 & $4.30 \mathrm{e}-30$ \\
\hline ORF 51 & gp51 & + & 36644 & 37099 & 152 & - & - & - & - \\
\hline ORF 52 & gp52 & + & 37096 & 37713 & 206 & cd00529 & Holliday junction resolvases (HJRs) & 38,38 & $3.22 \mathrm{e}-04$ \\
\hline ORF 53 & gp53 & + & 37710 & 37985 & 92 & - & - & - & - \\
\hline ORF 54 & gp54 & + & 37991 & 38428 & 146 & - & - & - & - \\
\hline ORF 55 & gp55 & + & 38425 & 38775 & 117 & - & - & - & - \\
\hline ORF 56 & gp56 & + & 38788 & 39564 & 259 & - & - & - & - \\
\hline ORF 57 & gp57 & + & 39567 & 40202 & 212 & - & - & - & - \\
\hline ORF 58 & gp58 & + & 40199 & 40402 & 68 & - & - & - & - \\
\hline ORF 59 & gp59 & + & 40399 & 40926 & 176 & - & - & - & - \\
\hline ORF 60 & gp60 & + & 40923 & 41120 & 66 & - & - & - & - \\
\hline ORF 61 & gp61 & + & 41153 & 41506 & 118 & - & - & - & - \\
\hline ORF 62 & gp62 & + & 41503 & 42369 & 289 & - & - & - & - \\
\hline ORF 63 & gp63 & + & 42366 & 42692 & 109 & - & - & - & - \\
\hline ORF 64 & gp64 & + & 42689 & 42814 & 42 & pfam10969 & Protein of unknown function (DUF2771) & 35,51 & $1.35 \mathrm{e}-04$ \\
\hline ORF 65 & gp65 & + & 42811 & 43368 & 186 & - & - & - & - \\
\hline ORF 66 & gp66 & + & 43466 & 44308 & 281 & - & - & - & - \\
\hline ORF 67 & gp67 & - & 44375 & 44590 & 72 & pfam02604 & Antitoxin Phd_YefM & 30,73 & $5.22 \mathrm{e}-03$ \\
\hline ORF 68 & gp68 & + & 44674 & 46254 & 527 & - & - & - & - \\
\hline ORF 69 & gp69 & + & 46345 & 47619 & 425 & - & - & - & - \\
\hline ORF 70 & gp70 & + & 47651 & 47743 & 31 & - & - & - & - \\
\hline ORF 71 & gp71 & + & 47817 & 47996 & 60 & - & - & - & - \\
\hline ORF 72 & gp72 & + & 48073 & 48510 & 146 & cd00397 & DNA breaking-rejoining enzymes & 40,54 & $2.27 e-05$ \\
\hline ORF 73 & gp73 & - & 49011 & 49772 & 254 & - & - & - & - \\
\hline ORF 74 & gp74 & + & 49506 & 49766 & 87 & - & - & - & - \\
\hline ORF 75 & gp75 & + & 49841 & 49996 & 52 & - & - & - & - \\
\hline ORF 76 & gp76 & + & 49993 & 50292 & 100 & cd00085 & HNH nucleases & 38,22 & $1.45 e-05$ \\
\hline ORF 77 & gp77 & + & 50587 & 51171 & 195 & COG4983 & Uncharacterized protein & 79,98 & $9.19 \mathrm{e}-18$ \\
\hline ORF 78 & gp78 & + & 51278 & 51349 & 24 & - & - & - & - \\
\hline ORF 79 & gp79 & - & 51714 & 52163 & 150 & - & - & - & - \\
\hline ORF 80 & gp80 & - & 52167 & 53399 & 411 & - & - & - & - \\
\hline ORF 81 & gp81 & - & 53709 & 54161 & 151 & - & - & - & - \\
\hline ORF 82 & gp82 & + & 54647 & 55672 & 342 & pfam06381 & Protein of unknown function (DUF1073) & 39,22 & $1.07 e-03$ \\
\hline ORF 83 & gp83 & - & 55695 & 55889 & 65 & - & - & - & - \\
\hline ORF 84 & gp84 & + & 55948 & 56844 & 299 & TIGR01641 & phage putative head morphogenesis protein & 59,7 & $1.40 \mathrm{e}-11$ \\
\hline ORF 85 & gp85 & - & 56884 & 57198 & 105 & PRK13502 & transcriptional activator RhaR & 32,72 & $8.64 \mathrm{e}-03$ \\
\hline ORF 86 & gp86 & + & 57346 & 57642 & 99 & - & - & - & - \\
\hline ORF 87 & gp87 & + & 57698 & 57847 & 50 & - & - & - & - \\
\hline ORF 88 & gp88 & + & 58134 & 58682 & 183 & - & - & - & - \\
\hline ORF 89 & gp89 & - & 58679 & 59956 & 426 & COG1783 & Phage terminase_3 & 161 & $6.32 \mathrm{e}-45$ \\
\hline ORF 90 & gp90 & - & 60233 & 60691 & 153 & - & - & - & - \\
\hline ORF 91 & gp91 & - & 60684 & 60932 & 83 & - & - & - & - \\
\hline
\end{tabular}


Table 3 Related Conserved Domains (CD) to the detected Phamilies using Phamerator

\begin{tabular}{|c|c|c|c|c|c|}
\hline Pham & Conserves Domains (CD) & Number of members & Mean translation length & Phage Sf1 & Phage Sf3 \\
\hline 1 & - & 2 & 136 & ORF 21 & ORF 1 \\
\hline 2 & - & 2 & 552 & ORF 22 & ORF 2 \\
\hline 3 & Phage portal protein & 2 & 475 & ORF 23 & ORF 3 \\
\hline 4 & - & 2 & 266 & ORF 24 & ORF 4 \\
\hline 5 & - & 2 & 249 & ORF 25 & ORF 5 \\
\hline 6 & Bacteriophage lambda head decoration protein $D$ & 2 & 130 & ORF 26 & ORF 6 \\
\hline 7 & Phage major capsid protein $\mathrm{E}$ & 2 & 348 & ORF 27 & ORF 7 \\
\hline 8 & - & 2 & 107 & ORF 28 & ORF 8 \\
\hline 9 & Phage protein Gp19 & 2 & 147 & ORF 29 & ORF 9 \\
\hline 10 & - & 2 & 117 & ORF 30 & ORF 10 \\
\hline 11 & - & 2 & 93 & ORF 31 & ORF 11 \\
\hline 12 & Terminase_4 superfamily & 3 & 132,3333 & ORF 1, ORF 32 & ORF 12 \\
\hline 13 & - & 2 & 221 & ORF 33 & ORF 13 \\
\hline 14 & - & 2 & 107 & ORF 34 & ORF 14 \\
\hline 15 & - & 2 & 142 & ORF 35 & ORF 15 \\
\hline 16 & - & 2 & 296 & ORF 37 & ORF 17 \\
\hline 17 & - & 2 & 381 & ORF 38 & ORF 18 \\
\hline 18 & - & 2 & 308 & ORF 39 & ORF 19 \\
\hline 19 & - & 2 & 205 & ORF 40 & ORF 20 \\
\hline 20 & Pectate lyase superfamily protein & 2 & 674 & ORF 41 & ORF 21 \\
\hline 21 & Peptidoglycan recognition proteins (PGRPs) & 2 & 275 & ORF 42 & ORF 22 \\
\hline 22 & - & 2 & 83 & ORF 43 & ORF 23 \\
\hline 23 & YabA & 2 & 110 & ORF 44 & ORF 24 \\
\hline 24 & Helix-turn-helix XRE-family like proteins & 2 & 407 & ORF 46 & ORF 26 \\
\hline 25 & - & 2 & 89 & ORF 47 & ORF 27 \\
\hline 26 & - & 2 & 64 & ORF 48 & ORF 28 \\
\hline 27 & - & 2 & 172 & ORF 49 & ORF 29 \\
\hline 28 & - & 2 & 160 & ORF 50 & ORF 30 \\
\hline 29 & - & 2 & 34,5 & ORF 51 & ORF 31 \\
\hline 30 & Histidine kinase-like ATPases & 2 & 149 & ORF 52 & ORF 32 \\
\hline
\end{tabular}

is involved in remodelling cell walls, it is clear that the divergence from the ancestral protein over time has allowed different micro-organisms to target a range of pectin-like substrates while the overall structure has been maintained [75]. orf42 (Sf1) and orf22 (Sf3) are members of pham n.21 and classified as peptidoglycan recognition proteins (PGRPs), an innate class of immunity molecules present in insects, mollusks, echinoderms, and vertebrates that by interacting with peptidoglycan in the cell wall, rather than permeabilizing bacterial membranes, kills bacteria. These proteins were reported, at least in one carboxy-terminal domain, as homologous in bacteriophage and bacteria [76]. orf46 (Sf1) and orf26 (Sf3) are grouped in pham n.24 and were identified as helix-turn-helix (HTH) XREfamily-like proteins, one of the early studied regulatory DNA-binding proteins involved in metabolic regulation in bacteria. This class of genes encodes components to process environmental metabolites (e.g. lactose) and to produce interacting constituents in the development of a lytic or lysogenic pathway in phages. A common ancestor for all DNA-binding domains was suggested and, through its duplication and divergence, the diversity of transcription regulators that drive bacterial and phage genes was generated. The HTH fold investigations confirmed the significance of this module in DNA-protein interactions across a wide phylogenetic spectrum including a wide variety of phages [77].

orf26 (Sf1) and orf6 (Sf3), members of pham n. 6, were classified as bacteriophage lambda head decoration protein D. Since the protein allows for the display of many copies of a foreign protein, which is advantageous for displaying weak ligands for affinity selection, a useful 
platform for phage polypeptide display was recently developed [78]. Interestingly, orf32 in Sf1 and orf12 in Sf3 were not assigned functions previously, although they belong to the pham $\mathrm{n} .12$ together with orf 1 (Sf1) which is classified as terminase_4.

A standard Nucleotide NCBI BLAST (blastn) search was developed using both Sf1 and Sf3 phage whole genome sequences as a query against a non-redundant nucleotide sequences database. Starting from a whole phage dataset (https://www.ncbi.nlm.nih.gov/) the available phage genomes with the best identity percentages (VWB and SV1) were chosen and a pictogram was developed (Fig. 4). Seventy-eight percent identity for both S. flavovirens phages compared to the complete genome of

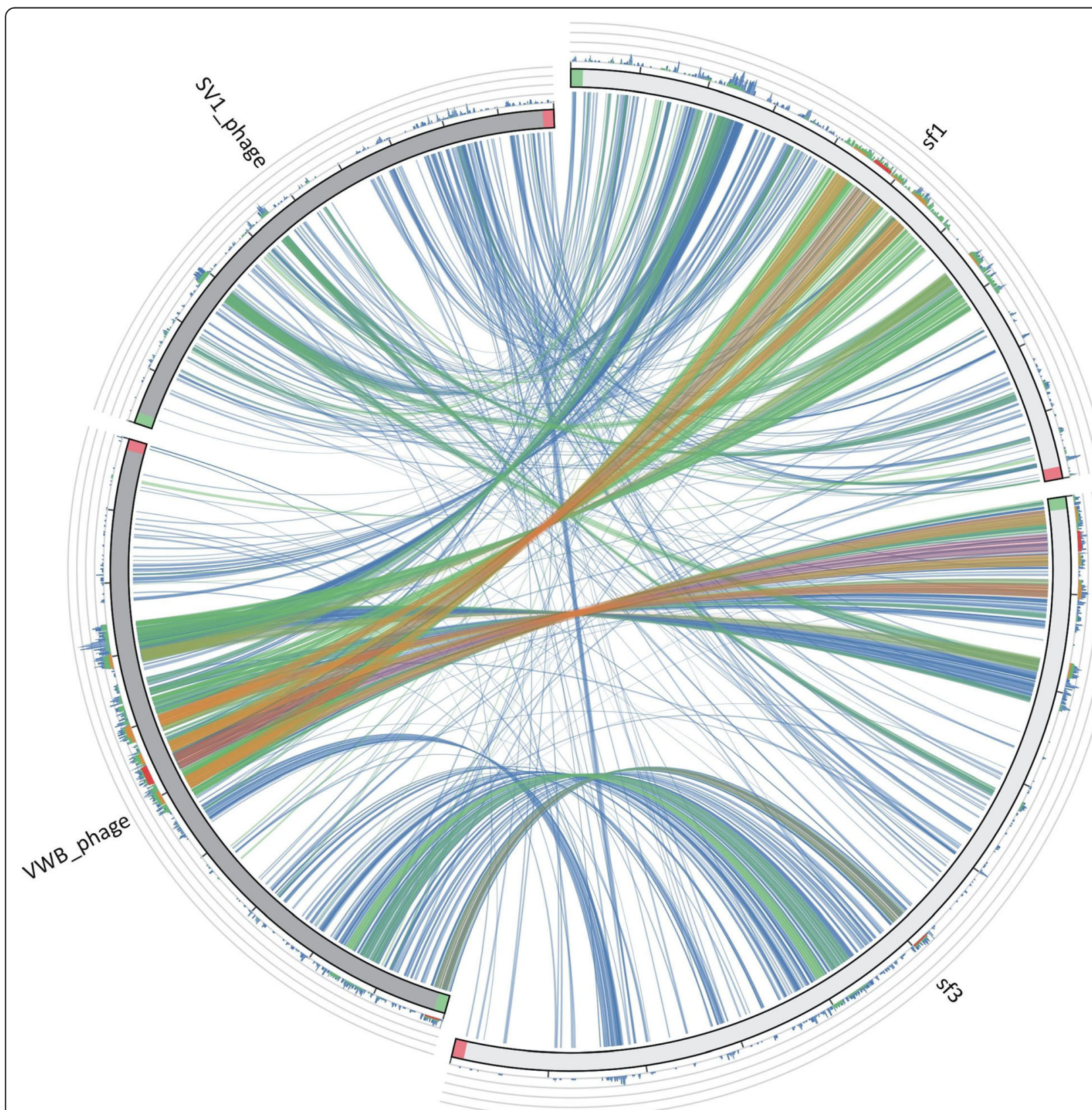

Fig. 4 Sequence similarities among Sf1, Sf3, WWB and SV1 phages. The picture shows the results of the BLAST local alignments using Sf1 and Sf3 as a query against the WWB and SV1 phages sequences. The different colours (blue, green, orange and red) represent the overall quality of the aligned segments along the phage sequences, evaluated on the basis of the bit-score values from the worst to the best score (blue to red). The bit-score is a normalized version of the score value obtained by BLAST searches, expressed in bits. The height of the coloured bars in the histogram shows how many times each colour hits a specific fragment of the other phage sequences. A twist in a ribbon indicates that the local alignment is inverted (query and database sequence on opposite strands) 
bacteriophage VWB, isolated from $S$. venezuelae strain ETH 14630 (AY320035.2), was exhibited (with 29\% and $36 \%$ of coverage for Sf1 and Sf3, respectively), while $75 \%$ of identity for both studied phages with $S$. venezuelae phage SV1 (JX182371.1) was reported, but with low query coverage (11\% for Sf1 and $14 \%$ for Sf3), probably due to the phylogenetic distance between the compared phages.

The alignment of both Sf1 and Sf3 genomes against the sequences of VWB phage, carried out by Mauve software, revealed that most hits occurred around a $13 \mathrm{~Kb}$ region (Fig. 4). The approximate location of this region were (18000-31000) within the Sf1 genome, $(1-13000)$ in the Sf3 genome and (23000-36000) in the VWB genome. On the contrary, the alignment of both $S$. flavovirens phage genomes versus the sequences of SV1 showed only a short region $(\sim 1 \mathrm{~Kb})$ with moderate bit score ranging from
9691-10707 and 10300-11208 in the genomes of Sf1 and Sf3, respectively, consistent with the low sequence coverage obtained.

The MCPs diversity between Sf1, Sf3 and 20 related Streptomyces phages, due to a combination of illegitimate and homologous recombination [79] and mutational drift, was also evaluated. The current investigation highlighted the hybrid generation between phage genera [80] or phage families [81]. Twenty-two Streptomyces phages were grouped in five main branches (Fig. 5). The Lannister MCP shared a close evolutionary relationship with the Izzy, Aaronocolus, and Caliburn sequences, demonstrating that phages may undergo genetic exchange by horizontal gene transfer from a large shared pool [4] and that horizontal gene transfer between phages is a component of their evolution. Numerous gene exchanges

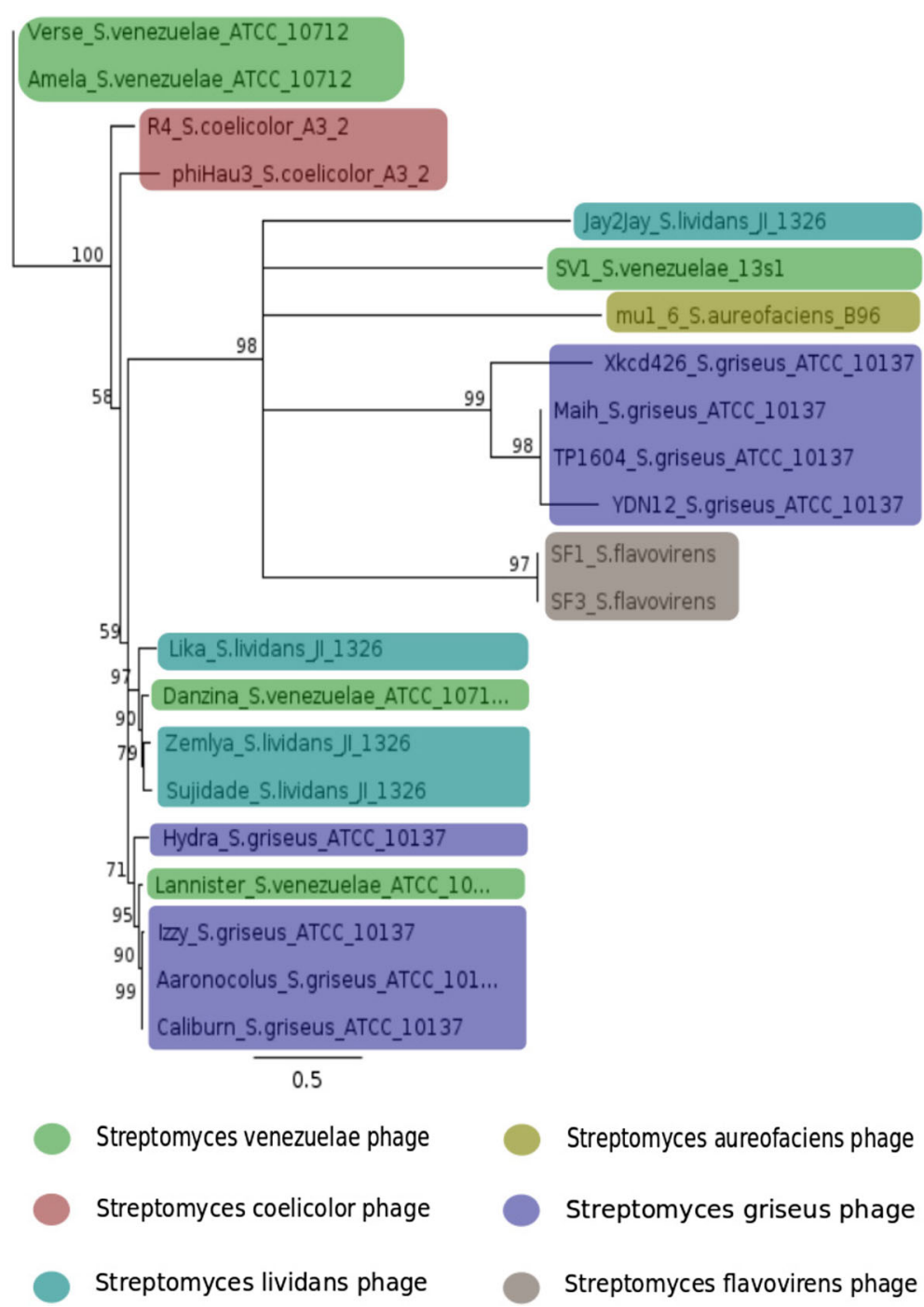

Fig. 5 Phylogenetic analysis of studied phages and other members (20) of the Streptomyces phages group based on MCPs. Bootstrap values indicate the number of times a node was supported in 1000 resampling replications 
within each major clade and core phage functions do not appear to have co-evolved with specific hosts [82].

Our phylogenetic analysis is useful for further studies, since both Sf1 and Sf3 were recovered in a clade that included phages that infect Streptomyces species but most of these phages (Maih, YDN12, Xkcd426 and TP1604) were members of the BG phage cluster; this clustering does not represent a phylogenetic or taxonomic grouping but rather provides a framework for reflecting their overall genome relationships and for identifying genes that have been recently exchanged and their genomic context $[83,84]$. Moreover, Sf1 and Sf3 grouped in a separate branch, indicating that isolated phages belong to the BG phage cluster but represent a different sub-cluster.

\section{Conclusion}

Recently, large advances have occurred in phage genomics; nevertheless,the full extent of phage diversity and evolutionary pathways are yet unknown. With the advent of NGS technologies a much greater volume of transcriptome and genome sequences is available and we can therefore expect an increased flow of new data in upcoming years. Current assessment suggests that more than 1031 phages exist on earth, representing more than ten million phage "species". Of these, less than 6000 have been observed using electron microscopy and fewer than 1000 genomes have been sequenced. The available sequences show that the majority of phages analyzed are tailed phages belonging to the family Siphoviridae, but less is known about the degree of their genetic diversity. The genomic characterization of phages is necessary to evaluate their important ecological impact. In spite of their ubiquity, phages have not yet been characterized for many bacterial genera. In the present study, biological, physiochemical and genome sequences of two new virulent Streptomyces phages are presented, representing the first genomic report of S. flavovirens phages which may represent a new sub-cluster of the BG Streptomyces phage cluster.

\section{Abbreviations \\ dsDNA: Double-stranded DNA; HJRs: Holliday junction resolvases; HTH: Helix-turn-helix; LT: Lytic transglycosylase; MCP: Major capsid protein; NCBI: National Center for Biotechnology Information; NGS: New Generation Sequencing; ORFs: Open reading frames; PGRPs: Peptidoglycan recognition proteins; Phages: Bacteriophages; REX: RNA exonuclease; TDP: Thymidine diphosphate; TMP: Thymidine monophosphate; TMPK: Thymidine monophosphate kinase; TTP: Thymidine triphosphate}

\section{Acknowledgement \\ The authors would like to thank the Center for Research in Agricultural Genomics (CRAG) service laboratory, Barcelona, Spain for providing the sequencing instruments and reagents used in the study, Ezio Fontana, IBBR-CNR, Palermo, Italy for his advice and discussion about the whole genome data analysis and Heather Esson, Biology Center ASCR, Institute of Parasitology, Czech Republic for assistance with language editing.}

\section{Funding}

This work does not obtained any fund.

\section{Availability of data and materials}

The complete genome sequences of Sf1 and Sf3 phages were deposited in the National Center for Biotechnology Information (NCBI) GenBank under accession numbers (KT221033 and KT221034), respectively.

\section{Authors' contributions}

All authors conceived and designed the experiments; AS carried out the experiments and performed the bioinformatics and statistical analysis; AS and FM compiled the results and drafted the manuscript. All the authors read and approved the final manuscript.

\section{Competing interests}

The authors declare that they have no competing interests.

\section{Consent for publication}

Not applicable.

\section{Ethics approval and consent to participate}

This article does not contain any studies with human participants or animals performed by any of the authors. Informed consent was obtained from all individual participants included in the study.

\section{Author details}

${ }^{1}$ Genetic Department, Faculty of Agriculture, Ain Shams University, Cairo 11241, Egypt. ${ }^{2}$ Institute of Parasitology, Biology Centre, Czech Academy of Sciences, 37005 České Budějovice, Czechia. ${ }^{3}$ Institute of Biosciences and Bioresources (IBBR), National Research Council (CNR) of Italy, 90129 Palermo, Italy. ${ }^{4}$ Central Lab. of Organic Agriculture, Agricultural Research Center, Giza 12619, Egypt. ${ }^{5}$ Botany and Microbiology Department, Faculty of Science, Helwan University, Ain-Helwan, Cairo 11970, Egypt. ${ }^{6}$ Microbiology

Department, Faculty of Agriculture, Ain Shams University, Cairo 11241, Egypt.

Received: 26 August 2016 Accepted: 24 January 2017

Published online: 03 March 2017

\section{References}

1. Klumpp J, Fouts DE, Sozhamannan S. Next generation sequencing technologies and the changing landscape of phage genomics. Bacteriophage. 2012;2(3):190-9.

2. Sandmeier H. Acquisition and rearrangement of sequence motifs in the evolution of bacteriophage tail fibres. Mol Microbiol. 1994;12(3):343-50.

3. Juhala RJ, Ford ME, Duda RL, et al. Genomic sequences of bacteriophages HK97 and HK022: pervasive genetic mosaicism in the lambdoid bacteriophages. J Mol Biol. 2000;299:27-51.

4. Hendrix RW, Smith MCM, Burns RN, et al. Evolutionary relationships among diverse bacteriophages and prophages: all the world's a phage. Proc Natl Acad Sci U S A. 1999:96:2192-7.

5. Hendrix RW. Bacteriophage genomics. Current Opinion in Microbiol. 2003;6:506-11.

6. Bradley SG, Ritzi D. Electron microscopical studies of actinophage multiplication. J Gen Virol. 1967;1 (3):285-90.

7. Bull AT, Ward AC, Goodfellow M. Search and discovery strategies for biotechnology: the paradigm shift. Microbiol Mol Biol Rev. 2000;64:573-606.

8. Ipek KD. Actinophages as indicators of actinomycete taxa in marine environments. Antonie Van Leeuwenhoek. 2005;87:19-28.

9. Korn-Wendish F, Schneider J. Phage typing-a useful tool in actinomycete systematics. Gene. 1992;115:243-7.

10. Williams ST, Locci R, Beswick A, et al. Detection and identification of novel actinomycetes. Res Microbiol. 1993;144(8):653-6.

11. Ackerman HW, Berthiaume L, Jones LA. New actinophage species. InterVirology. 1985;23:121-30.

12. Othman BA, Askora AA, Awny NM, et al. Virulent Bacteriophages for Streptomyces griseoflsvus Isolated from Soil. Pak J Biotechnol. 2008;5:109-18.

13. Ashelford KE, Day MJ, Bailey MJ, et al. In situ population dynamics of bacterial viruses in a terrestrial environment. Appl Environ Microbiol. 1999;65:169-74.

14. Ashelford KE, Day MJ, Fry JC. Elevated Abundance of Bacteriophage Infecting Bacteria in Soil. Appl Environ Microbiol. 2003;69(1):285-9.

15. Chater KF, Hopwood DA, Kieser T, et al. Gene cloning in Streptomyces. Curr Top Microbiol Immunol. 1982;96:69-95. 
16. Harris JE, Chater KF, Bruton CJ, et al. The restriction mapping of $\mathrm{C}$ gene deletions in Streptomyces bacteriophage 4C31 and their use in cloning vector development. Gene. 1983;22(2-3):167-74.

17. Oliver K. Grundwissen Pharmazeutische Biotechnologie. Vieweg + Teubner Verlag: Wiesbaden; 2002. ISBN 3-322-80124-1.

18. Satinder KB, Gurpreet SD, Carlos RS. Biotransformation of Waste Biomass into High Value Biochemicals. New York, NY: Springer New York; 2014.

19. Eisenstein M. Oxford Nanopore announcement sets sequencing sector abuzz. Nat Biotechnol. 2012;30:295-6.

20. Srivatsan A, Han Y, Peng J, et al. High-precision, whole-genome sequencing of laboratory strains facilitates genetic studies. PLoS Genet 2008, doi:10.1371/journal.pgen.1000139.

21. Hatfull GF. Bacteriophage genomics. Curr Opin Microbiol. 2008;11:447-53.

22. Marei EM, Elbaz RM. Isolation and Molecular Characterization of Three Virulent Actinophages Specific for Streptomyces flavovirens. J Virol Res. 2013;2:12-7.

23. Lanning S, Williams ST. Methods for the direct isolation and enumeration of actinophages in soil. J Gen Microbiol. 1982;128:2063-71.

24. Dowding JE. Characterization of a bacteriophage virulent for Streptomyces coelicolor A3(2). J Gen Microbiol. 1973;76:163-76.

25. ADAMS MH. Methods of study of bacterial viruses. Methods in Med Research. 1950;2:1-73.

26. Paunikar WN, Sanmukh SG, Ghosh TK. Effect of metal ions and chemical solvents on the adsorption of Salmonella phage on Salmonella choleraesuis subspecies indica. Int J of Pharma and Biosci. 2012;3(1):181-90.

27. Adams MH. Bacteriophages. New York: Interscience; 1959.

28. Kieser T, Bibb MJ, Buttner MJ, et al. Practical Streptomyces Genetics. Norwich: The John Innes Foundation; 2000.

29. Lohsem M, Bolger AM, Nagel A, et al. RobiNA: a user-friendly, integrated software solution for RNA-Seq-based transcriptomics. Nucleic Acids Res 2012, doi:10.1093/nar/gks540.

30. Schatz MC, Phillippy AM, Shneiderman B, et al. Hawkeye: an interactive visual analytics tool for genome assemblies. Genome Biology 2007 doi:10.1186/gb-2007-8-3-r34.

31. Hatfull GF, Jacobs-Sera D, Lawrence JG, et al. Comparative genomic analysis of sixty mycobacteriophage genomes: Genome clustering, gene acquisition and gene size. J Mol Biol. 2010;397(1):119-43.

32. Dobbins AT, George Jr M, Basham DA, et al. Complete Genomic Sequence of the Virulent Salmonella Bacteriophage SP6. J Bacteriol. 2004;186(7):1933-44.

33. Cresawn SG, Bogel M, Day N, et al. Phamerator: a bioinformatic tool for comparative bacteriophage genomics. BMC Bioinformatics. 2011;12:395.

34. Altschul SF, Gish W, Miller W, et al. Basic local alignment search tool. J Mol Biol. 1990;215(3):403-10.

35. Darling AE, Mau B, Perna NT. ProgressiveMauve: multiple genome alignment with gene gain, loss and rearrangement. PLoS One 2010 doi:10.1371/journal.pone.0011147.

36. Krzywinski M, Schein J, Birol I, et al. Circos: an information aesthetic for comparative genomics. Genome Res. 2009;19(9):1639-45

37. Darzentas N. Circoletto: visualizing sequence similarity with Circos. Bioinformatics. 2010;26(20):2620-1.

38. Kearse $M$, et al. Geneious basic: an integrated and extendable desktop software platform for the organization and analysis of sequence data. Bioinformatics. 2012;28:1647-9.

39. Anné J, Van Mellaert L, Decock B, et al. Further biological and molecular characterization of actinophage WWB. J Gen Microbiol. 1990;136:1365-72.

40. Pringsulaka O, Chvanich S, Doi K, et al. Characteristics and Distribution of Actinophages Isolated from Thai Soil Samples. Sci Asia. 2004;30:223-30.

41. AlKhazindar M, Sayed ETA, Khalil MS, et al. Isolation and Characterization of Two Phages Infecting Streptomyces scabies. Res J Pharm, Biol Chem Sci. 2016;7(2):1351-63.

42. Binetti A, Quiberoni A, Reinheimer J. Phage adsorption to Streptococcus thermophilus. Influence of environmental factors and characterization of cell-receptors. Food Res Int. 2002;35:73-83.

43. Quiberoni A, Guglielmotti D, Binetti A, et al. Characterization of three Lactobacillus delbrueckii sub sp. bulgaricus phages and the physiochemical analysis of phage adsorption. J Appl Microbiol. 2004;96:340-51.

44. Robert B, Charles PJ. Characterization of the effect of aluminum metal on poliovirus. J of Indus Microbiol. 1988;3:33-8.

45. Brudno M, Do CB, Cooper GM, et al. NISC Comparative sequencing program LAGAN and multi-LAGAN: efficient tools for large-scale multiple alignment of genomic DNA. Genome Res. 2003;13(4):721-31.
46. Casjen SR, Thuman-Commike PA. Evolution of mosaically related bacteriophage genomes seen through the lens of phage P22 virion assembly. Virology. 2011;411:393-415.

47. Hendrix RW, Lawrence JG, Hatfull GF, et al. The origins and ongoing evolution of viruses. Trends Microbiol. 2000;8(11):504-8.

48. Petrovski S, Tillett D, Seviour RJ. Genome sequences and characterization of the Gordonia phages GTE5 and GRU1 and their use as potential biocontrol agents. Appl Environ Microbiol. 2012;78:42-7.

49. Rohwer F, Edwards R. The phage proteomic tree: a genome-based taxonomy of phage. J Bacteriol. 2002;184:4529-5.

50. Marchler-Bauer A, Derbyshire MK, Gonzales NR, et al. CDD: NCBI's conserved domain database. Nucleic Acids Res. 2015;43(Database issue):222-6.

51. Van Dessel W, Van Mellaert L, Liesegang H, et al. Complete genomic nucleotide sequence and analysis of the temperate bacteriophage WWB. J Anne Virology. 2005;331:325-37.

52. Grande L, Michelacci V, Tozzoli R, et al. Whole genome sequence comparison of vt×2-converting phages from Enteroaggregative Haemorrhagic Escherichia coli strains. BMC Genomics. 2014. doi:10.1186/1471-2164-15-574.

53. Leon-Velarde CG, Kropinski AM, Chen S, et al. Complete genome sequence of bacteriophage VB_YenP_AP5 which infects Yersinia enterocolitica of serotype 0:3. Virol J. 2014. doi:10.1186/1743-422X-11-188.

54. Schouler C, Ehrlich SD, Chopin MC. Sequence and organization of the lactococcal prolate-headed blL67 phage genome. Microbiology. 1994;140:3061-9.

55. Ford ME, Sarkis GJ, Belanger AE, et al. Genome structure of mycobacteriophage D29: implications for phage evolution. J Mol Biol. 1998;279(1):143-64.

56. Kropinski AM, Kovalyova IV, Billington SJ, et al. The genome of epsilon15, a serotype-converting, Group E1 Salmonella enterica-specific bacteriophage. Virology. 2007;369(2):234-44.

57. Katsura I. Structure and inherent properties of the bacteriophage lambda head shell. VI. DNA-packaging-defective mutants in the major capsid protein. Jol Biol. 1989:205(2):397-405

58. Lurz R, Orlova EV, Günther D, et al. Structural organisation of the head-totail interface of a bacterial virus. J Mol Biol. 2001:310(5):1027-37.

59. Gual A, Camacho AG, Alonso JC. Functional analysis of the terminase large subunit, G2P, of Bacillus subtilis bacteriophage SPP1. J Biol Chem. 2000;275(45):35311-9.

60. Noirot-Gros MF, Velten M, Yoshimura M, et al. Functional dissection of YabA, a negative regulator of DNA replication initiation in Bacillus subtilis. Proc Natl Acad Sci U S A. 2006;103(7):2368-73.

61. Hayashi M, Ogura Y, Harry EJ, et al. Bacillus subtilis YabA is involved in determining the timing and synchrony of replication initiation. FEMS Microbiol Lett. 2005;247(1):73-9.

62. Luscombe NM, Austin SE, Berman HM, et al. An overview of the structures of protein-DNA complexes. Genome Biol 2000, doi:10.1186/gb-2000-1-1-reviews001.

63. Dutta $R$, Inouye M. GHKL, An emergent ATPase/kinase superfamily. Trends Biochem Sci. 2000:25(1):24-8.

64. Hvorup RN, Winnen B, Chang AB, et al. The multidrug/oligosaccharidyllipid/polysaccharide (MOP) exporter superfamily. Eur J Biochem. 2003; 270(5):799-813

65. Satoh A, Wang Y, Malsam J, et al. Golgin-84 is a rab1 binding partner involved in Golgi structure. Traffic. 2003;4(3):153-61.

66. Bruner SD, Norman DP, Verdine GL. Structural basis for recognition and repair of the endogenous mutagen 8-oxoguanine in DNA. Nature. 2000:403(6772):859-66.

67. Ibrahim H, Wilusz J, Wilusz CJ. RNA recognition by 3'-to-5' exonucleases: the substrate perspective. Biochim Biophys Acta. 2008;1779(4):256-65.

68. Aravind L, Makarova KS, Koonin EV. SURVEY AND SUMMARY: holliday junction resolvases and related nucleases: identification of new families, phyletic distribution and evolutionary trajectories. Nucleic Acids Res. 2000;28(18):3417-32

69. Ku WY, Liu YW, Hsu YC, et al. The zinc ion in the HNH motif of the endonuclease domain of colicin E7 is not required for DNA binding but is essential for DNA hydrolysis. Nucleic Acids Res. 2002;30(7):1670-8.

70. Cheng X, Zhang X, Pflugrath JW, et al. The structure of bacteriophage T7 lysozyme, a zinc amidase and an inhibitor of T7 RNA polymerase. Proc Natl Acad Sci U S A. 1994;91(9):4034-8.

71. Petrovski S, Seviour RJ, Tillett D. Genome characterization of the polyvalent Iytic bacteriophage GTE2 with the potential for biocontrol of Gordonia, Rhodococcus and Nocardia stabilized foams in activated sludge plants. Appl Environ Microbiol. 2011;77(12):3923-9. 
72. Petrovski S, Dyson ZA, Seviour RJ, et al. Small but sufficient: the Rhodococcus phage RRH1 has the smallest known Siphoviridae genome at $14.2 \mathrm{~kb}$. J Virol. 2012;86:358-63.

73. Smith KC, Castro-Nallar E, Fisher JNB, et al. Phage cluster relationships identified through single gene analysis. BMC Genomics. 2013;14:410.

74. Sullivan MB, Coleman ML, Quinlivan V, et al. Portal protein diversity and phage ecology. Environ Microbiol. 2008;10(10):2810-23.

75. Hooton SP, Timms AR, Rowsell J, et al. Salmonella Typhimurium-specific bacteriophage FSH19 and the origins of species specificity in the Vi01-like phage family. Virol J. 2011:8:498.

76. Dziarski R, Gupta D. Protein family review The peptidoglycan recognition proteins (PGRPs). Genome Biol. 2006;7:232.

77. Aravind $L$, Anantharaman $V$, Balaji $S$, et al. The many faces of the helix-turnhelix domain: Transcription regulation and beyond. FEMS Microbiol Rev. 2005;29:231-62

78. Wendt JL, Feiss M. A fragile lattice: replacing bacteriophage E's head stability gene $\mathrm{D}$ with the shp gene of phage 21 generates the Mg2 +-dependent virus, E shp. Virology. 2004;326:41-6.

79. Clark AJ, Inwood W, Cloutier T, Dhillon TS. Nucleotide sequence of coliphage HK620 and the evolution of lambdoid phages. J Mol Biol. 2001;311:657-79.

80. Canchaya C, Fournous G, Chibani-Chennoufi S, Dillmann ML, Brussow H. Phage as agents of lateral gene transfer. Curr Opin Microbiol. 2003;6:417-24.

81. Recktenwald J, Schmidt H. The nucleotide sequence of Shiga toxin (Stx) 2eencoding phage phiP27 is not related to other Stx phage genomes, but the modular genetic structure is conserved. Infect Immun. 2002;70:1896-908.

82. Dekel-Bird NP, Avrani S, Sabehi G, Pekarsky I, Marston MF, Kirzner S, Lindell D. Diversity and evolutionary relationships of T7-like podoviruses infecting marine cyanobacteria. Environ Microbiol. 2013;15:1476-91.

83. Lawrence JG, Hatfull GF, Hendrix RW. Imbroglios of viral taxonomy: genetic exchange and failings of phenetic approaches. J Bacteriol. 2002;184:4891-905.

84. Lima-Mendez G, Van Helden J, Toussaint A, Leplae R. Reticulate representation of evolutionary and functional relationships between phage genomes. Mol Biol Evol. 2008;25:762-77.

\section{Submit your next manuscript to BioMed Central and we will help you at every step:}

- We accept pre-submission inquiries

- Our selector tool helps you to find the most relevant journal

- We provide round the clock customer support

- Convenient online submission

- Thorough peer review

- Inclusion in PubMed and all major indexing services

- Maximum visibility for your research

Submit your manuscript at www.biomedcentral.com/submit 